\title{
Partial Currarino Syndrome in Adulthood Mistaken for a Simple Presacral Mass
}

\author{
Alaa El-Kheir ${ }^{1, *}$, Charif Khaled ${ }^{1, *}$, Raia Doumit ${ }^{2}$, Chawki Nohra ${ }^{3}$, Antoine Khoneisser ${ }^{1}$ \\ ${ }^{1}$ General Surgery Department, Faculty of Medical Sciences, Lebanese University, Beirut, Lebanon \\ ${ }^{2}$ Diagnostic Radiology Department, Faculty of Medical Sciences, Lebanese University, Beirut, Lebanon \\ ${ }^{3}$ Neurosurgery Department, Faculty of Medical Sciences, Lebanese University, Beirut, Lebanon \\ *Corresponding author(s): alaa.kheir@live.com, khaled.charif@hotmail.com
}

Received July 26, 2019; Revised August 29, 2019; Accepted September 20, 2019

\begin{abstract}
Currarino syndrome is a rare congenital disease and its appearance in adulthood is exceptional. It is neglected in the typical differential diagnosis of a presacral mass. This results in severe complications following simple mass resection.
\end{abstract}

Keywords: currarino syndrome, congenital disease, sacrococcygeal agenesis, presacral mass, epidermoid tumor

Cite This Article: Alaa El-Kheir, Charif Khaled, Raia Doumit, Chawki Nohra, and Antoine Khoneisser, "Partial Currarino Syndrome in Adulthood Mistaken for a Simple Presacral Mass." American Journal of Medical Case Reports, vol. 7, no. 12 (2019): 317-319. doi: 10.12691/ajmcr-7-12-4.

\section{Introduction}

Currarino syndrome (CS) is a rare congenital disease characterized by a triad of malformations. This Currarino triad consists of sacrococcygeal bone defect, presacral mass and anorectal malformation. [1] Other pathologies may also be associated; these consist of spinal dysraphism, spinal cord tethering, renal/ureteral anomalies, female internal genital or uterine malformations and various types of fistulas. [2] Due to the variable phenotypical presentations of the gene mutation causing this triad, symptoms vary substantially. [3] The syndrome is diagnosed during childhood most of the times; that is mainly due to imperforation of anus. Nevertheless, incomplete triad can present later in life as constipation. [4]

We hereby present a rare case of CS presenting in adulthood, operated at first for what was thought to be a simple presacral mass, without knowing of the existence of an association with other anomalies.

\section{Case}

A 33-year-old female patient presented to the clinic with complaints of exacerbating constipation and vague abdominal pain for a couple of years. Her past medical and surgical history was negative. Note that a colonoscopy had been performed a few months earlier and was within normal.

She was afebrile and her vital signs were within normal limits. Her physical exam was only significant for a latero-posterior mass on digital rectal exam; the mass was pushing the rectum contra-laterally. For better evaluation and assessment of the mass, an MRI was ordered and showed a well circumscribed mass in the pelvis [Figure 1]. However, the radiologist failed to mention in his final report the sacral segments and coccygeal agenesis that are seen in the last section of Figure 1.

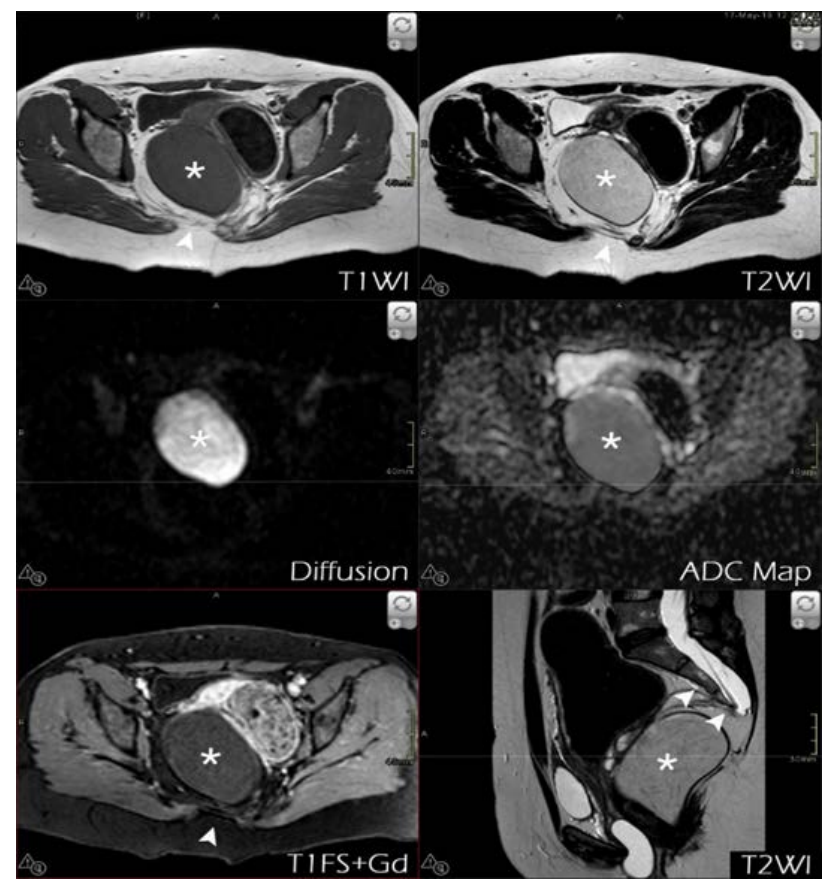

Figure 1. Multiparametric MRI of the pelvis: a presacral mass (asterisk) showing a hypointense signal on T1WI with thin wall without any post contrast ring-enhancement or intramural solid nodule, hyperintense signal on T2WI, restriction of diffusion seen as bright signal on DWI and hyposignal on ADC map, the latter being pathognomonic of epidermoid cyst. Note the last sacral segments and coccygeal agenesis (arrowheads)

The final differential diagnosis included: epidermoid cyst, dermoid cyst, cystic rectal duplication and tailgut cyst. After focusing only on the mass, the patient was 
consented for a surgical mass resection. The operation was done laparoscopically but resulted in a small vaginal injury which was primarily repaired on the spot.

Her post-op course included mild headache and lower limb weakness in the first 2 days. However, her vitals and labs remained normal. The patient improved on supportive treatment and was discharged on day 4. The final pathology result came back as an epidermoid cyst with an associated canal cyst and our patient was thought to require no further treatment.

On day 11 post-op, the patient presented to the ER for blood and fecal material secretions from the vagina. She was also complaining of excruciating headaches and was febrile $\left(39^{\circ} \mathrm{C}\right)$. Her white blood cell count was $6600 / \mathrm{mm} 3$ (normal range 4800-10800) with a CRP of $299 \mathrm{mg} / \mathrm{L}$ (normal range 0-6). CT of the brain and CT of the abdomen and pelvis were ordered urgently and showed: [Figure 2]

- Gaz inclusions in the arachnoid space...

- Meningeal enhancement consistent with meningitis

- $\quad$ Right pararectal fecaloid collection $4.7 * 4 * 3 \mathrm{cms}$

- Possibility of a colo-vaginal fistula

- Partial agenesis of the coccyx and non-fusion of the posteroinferior sacrum.

- Air bubbles at the level of the epidural space; possible communication between the dura and the collection.

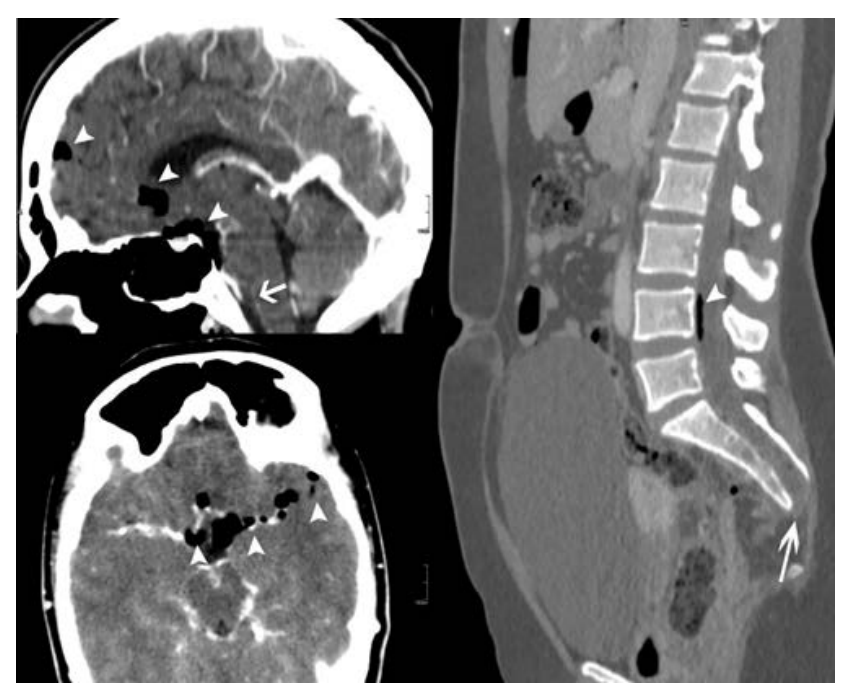

Figure 2. Axial and sagittal reformat enhanced-CT scanner of the brain and sagittal enhanced-CT scanner reformat of the abdomen and pelvis showing multiple air bubbles in the dural space (arrowheads), leptomeningeal enhancement (short arrow) suggestive of meningitis. Note the sacro-coccygeal anomaly with communication of the dural sac with the presacral space (long arrow).

Following these findings, an LP was ordered and performed by a neurologist. LP drained purulent cerebrospinal fluid and cultures later showed E. Coli. After a multidisciplinary meeting, the patient was started on broad spectrum antibiotics and transferred to the operating room for a laparotomy for lavage and control of the source of sepsis.

The fecaloid collection was drained with copious lavage, and a diverting loop colostomy was performed in order to stop the inflow of fecal material into the collection. Post-operatively, the patient was no longer febrile, improved mildly, although still complaining from her headache and lower limbs weakness. A lumbar MRI and a myelography was done to better assess the communication between the dura and the old collection, and confirmed its presence after passage of contrast into the presacral space [Figure 3].

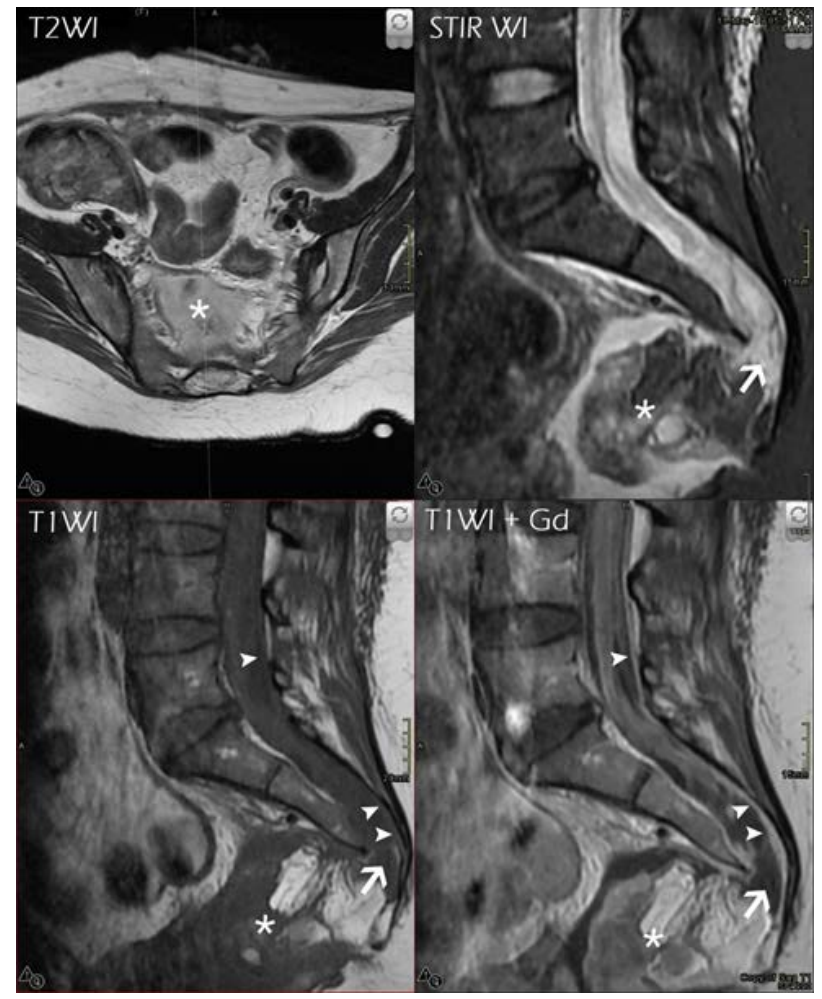

Figure 3. Multiparameter MRI cuts centered on the pelvis and the lumbo-sacral spine showing a heterogeneous partially enhancing collection in the presacral space (asterisk) with direct communication with the dural sac through a large defect (short arrow). Note the dural enhancement (arrowheads) suggestive of extension of the infectious/inflammatory process to the medullary canal

The neurosurgery team then decided to surgically close this fistula through a posterior approach. This operation was done a few days post the laparotomy. The neurosurgeon in charge had a difficulty doing a primary repair so he opted to patch the fistula with fat.

Our patient finally started improving. She no longer reported any headaches or lower limb weakness; her meningeal signs and symptoms had been cured. She was kept for a few days to continue the course of the antibiotics. The day before her discharge, she underwent a final CT which proved the closure of the fistula between the dural sac and the presacral space/collection.

Follow up will be done regularly over the next few weeks and the loop colostomy is planned to be closed in 6 weeks.

\section{Literature Review}

This syndrome was noted as early as 1837, but it wasn't until 1981 that Currarino, an American radiologist, described that the triad could occur from a single embryological process. He also noted members of the patient's family lacking one or two features of the malformations, [5] suggesting an incomplete form of the syndrome, although sacrococcygeal bone defect is almost 
always a part of this disease. [6] It can range from deviation of the coccyx to asymmetric hypoplasia of multiple distal sacral elements. [7] Possible presacral mass are most commonly anterior meningocele and benign teratomas. Enteric cysts, lipomas, dermoid and epidermoid cysts may also be seen. [6] Embryologically, Currarino et al. [5] explained these malformations by persistent abnormal adhesions between the endoderm and the neural ectoderm. This causes the notochord to split or to be displaced laterally, eventually preventing anterior fusion of vertebrae and possible formation of a fistula between the gut and the spinal canal. [5] Partial resorption of this fistula may form a meningocele or an enteric cyst, which can be complicated by nausea and headache during coughing or defecation, and even by meningitis. [7,8] If not treated early and aggressively, meningitis can be fatal. [9]

Presacral teratomas are thought to be formed by local enteric and neuroectodermal elements combined with mesodermal elements brought into the space by the developing somites. However, nowadays, it is thought that the causative factor of the syndrome may be in fact the caudal cell mass, which gives rise to the cloaca as well as the terminal spinal cord. Failure of dorsoventral separation of the caudal cell mass from the hindgut endoderm during late gastrulation may be the mechanism. This concept is supported by experiments on mice given a teratogen that targets the caudal cell mass and leading to CS. [10]

Inheritance of Currarino's syndrome is autosomal dominant in familial cases, and the homeobox gene motor neuron and pancreas homeobox-1 (MNX1) is implicated in almost all familial cases and in almost $30 \%$ of sporadic cases. [2] Cearns et al. reported 10 cases of CS patients with dysraphic anomalies and noticed that constipation was the most common presenting symptom (90\%). It may be associated with urinary dysfunction, lower limbs weakness and/or sacral swelling. [2] This association of constipation, sacral bony defect and a presacral mass, alongside with incomplete Currarino's syndrome is diagnosed later in life in only 19-20\%; whereas the complete form with anal stenosis is diagnosed before the age of 10 in more than $80 \%$. This is mainly explained by the severity of the triad in early childhood in the complete form [7].

In adulthood, the syndrome shows a higher predominance in females with a female:male ration of 8:1. The explanation of these findings may be due to complications of delivery and more frequent routine gynecological examinations in females. [7]

Radiologic modalities play an important role in diagnosis and follow up of this pathology. Characteristic imaging sings may be seen incidentally in asymptomatic patients. They most commonly tend to be sacral dysgenesis which can be seen on all imaging techniques, in addition to a presacral mass seen mainly on CT scan or MRI. But MRI surely remains the best imaging tool due to its ability to detect specifically the anorectal malformations and spinal anomalies, without ionizing radiation exposure. $[2,6]$

Surgery remains the treatment of choice for these patients, mainly for fear of malignant degeneration of the presacral mass, and because conservative management with laxatives and anal dilatation are not satisfactory. [7] Multiple approaches have been described: staged posterior sagittal anorectoplasty and repair of anterior mass, a trans-sacral approach for the presacral mass, and a combined anterior and posterior approach. However, in the study of Cearns et al [2], a combined neurosurgical and general surgical approach was performed in a single operation in all 10 patients. Spinal surgery was done through a posterior midline incision and presacral mass was resected through a trans-perineal approach, with a diverting colostomy in 4 patients. This option may be plausible, especially that none of these patients suffered from meningitis or any other surgery related complication post-operatively.

\section{References}

[1] Lynch, S. A. (2000). Autosomal dominant sacral agenesis: Currarino syndrome. Journal of Medical Genetics, 37(8), 561-566.

[2] Cearns, M. D., Hettige, S., De Coppi, P., \& Thompson, D. N. P. (2018). Currarino syndrome: repair of the dysraphic anomalies and resection of the presacral mass in a combined neurosurgical and general surgical approach. Journal of Neurosurgery: Pediatrics, 22(5), 584-590.

[3] Duru, S., Karabagli, H., Turkoglu, E., \& Erşahin, Y. (2013). Currarino syndrome: report of five consecutive patients. Child's Nervous System, 30(3), 547-552.

[4] Emans PJ, Kootstra G, Marcelis CL, Beuls EA, van Heurn LW (2005). The Currarino triad: the variable expression. J Pediatr Surg 40: $1238-1242$.

[5] Currarino, G., Coln, D., \& Votteler, T. (1981). Triad of anorectal, sacral, and presacral anomalies. American Journal of Roentgenology, 137(2), 395-398.

[6] Akay, S., Battal, B., Karaman, B., \& Bozkurt, Y. (2015). Complete Currarino Syndrome Recognized in Adulthood. Journal of Clinical Imaging Science, 5(1), 10.

[7] Köchling, J., Pistor, G., Brands, S., Nasir, R., \& Lanksch, W. (1996). The Currarino Syndrome - Hereditary Transmitted Syndrome of Anorectal, Sacral and Presacral Anomalies. Case Report and Review of the Literature. European Journal of Pediatric Surgery, 6(2), 114-119.

[8] Jeltema, H.-R., Broens, P. M. A., Brouwer, O. F., \& Groen, R. J. M. (2019). Severe bacterial meningitis due to an enterothecal fistula in a 6-year-old child with Currarino syndrome: evaluation of surgical strategy with review of the literature. Child's Nervous System, 35(7), 1129-1136.

[9] Al Qahtani, H. M., Suliman Aljoqiman, K., Arabi, H., Al Shaalan, H., \& Singh, S. (2016). Fatal Meningitis in a 14-Month-Old with Currarino Triad. Case Reports in Radiology, 2016, 1-5.

[10] Szumska, D., Pieles, G., Essalmani, R., Bilski, M., Mesnard, D., Kaur, K., et al. (2008). VACTERL/caudal regression/Currarino syndrome-like malformations in mice with mutation in the proprotein convertase Pcsk5. Genes \& Development, 22(11), 1465-1477. 